to produce some deformed oxyluciferins (Oxyln*) in luminous excited states depending on $\mathrm{pH}$, which can emit yellow-green $(560 \mathrm{~nm})$, red $(620 \mathrm{~nm})$ or deep-red $(670 \mathrm{~nm})$ lights, and $\mathrm{CO}_{2}{ }^{*}$, which still couples with Oxyln* differently. On the basis of recently reported crystal structures of wild-type Lucs from the Genji-botaru in complex with a LH2-AMP analogue (DLSA), and AMP plus Oxyln, we could succeed in finding out the most reasonable mechanisms to explain some key steps in each reaction groups mentioned above, using the TD-DFT/B3LYP/6-31G** method. Our proposed mechanisms are focussed on answering to the most fundamental question, respectively; (1) what kind of the transition state for luciferyladenylation is formed in the firefly Luc; (2) where and how the intersystem crossing would take place; (3) why the firefly bioluminescense is so efficient with respect to both the quantum yield and the energy conversion.

\section{S3-4 発光微生物の非線形発光挙動}

Non-linear bioluminescence behavior of luminous bacterium

Hajime Karatani (1), Shota Shishimoto (1), Kengo Kitadokoro (1).(1:Dept Biomolecular Engineering, Graduate School of Science and Technology, Kyoto Institute of Technology)

Bacterium bioluminescence (BL) is produced in luciferase reaction with $\mathrm{FMNH}_{2}$, $\mathrm{O}_{2}$ and an aldehyde. Some species bear fluorescent protein to cause the change in BL color. For example, Vibrio fischeri $\mathrm{Y} 1$ produces yellow BL peaking around $535 \mathrm{~nm}$ with yellow fluorescent protein. $V$. fischeri $\mathrm{Y} 1$ changes the BL color swiftly in response to the change in $\mathrm{pO}_{2}$. The measurement of $\mathrm{BL}$ at various $p \mathrm{O}_{2}$ showed that an increase in $p \mathrm{O}_{2}$ results in the enhancement of yellow $\mathrm{BL}$, and that the BL color varies to blue ( $c a .475 \mathrm{~nm}$ ) by lowering $p \mathrm{O}_{2}$. In a single cell level, an increase in a cell density seemed to cause the enhancement of the yellow BL intensity. The increase in the yellow BL intensity, relating to a cell density, might suggest that $V$. fischeri $\mathrm{Y} 1$ modulates the spectral distribution in the cell division cycle. Luminous colony formed by the repetitious cell division on an agar plate also showed a characteristic non-linear BL behavior. A single colony regularly grows exhibiting a bright glowing ring close to the frontline of growing colony. $\mathrm{BL}$ imaging of the growing colony showed that supplying $\mathrm{O}_{2}$ triggers off an occurrence of new glowing ring in the dim inside of the colony, and that the generated glowing ring gradually disappears when supplying $\mathrm{O}_{2}$ is halted. Such a flickering light pattern repetitively occurred in accordance with the presence and absence of $\mathrm{O}_{2}$-impetus. Such a flickering pattern was evidently observed on the colony of Photobacterium phosphoreum. In this presentation, we will explain the aforementioned non-linear BL behavior.

\section{S3-5 発光イメージングによる細胞機能の解析技術}

Luminescence imaging technology for cell-based analysis

Hirobumi Suzuki (Research and Development Division, Olympus Corporation)

Luciferase reporter assay system is widely used for the study of gene expression, signal transduction and other cellular activities. The luciferase assay is conventionally performed by photon-counting luminometer method. In this system, light emitting from cells is measured as an integrated value through all cells. At an embryo, tissue and cell-cell contact level, it is needed to monitor the expression activity of genes of interest in each cell spatially and chronologically as image. To obtain a luminescence image, ultra-low imaging technology, such as photon-counting CCD and liquid nitrogen cooled CCD cameras, has been required. We have successfully developed a new optical system for bioluminescence imaging using a conventional cooled CCD camera, and applied this microscope for cell-based analyses such as promoter assay of some genes, calcium signal transduction and cytosolic ATP measurement during apoptosis, at single cell level. From the data, it is expected that the bioluminescence imaging assay at cellular level would contribute for further understanding of gene expression, signal transduction and other cellular activities.

\section{S3-6 生物発光で紐解く哺乳類の概日時計の分子・細胞ネットワーク \\ MOLECULAR AND CELLULAR NETWORKS OF MAMMALIAN CIRCADIAN CLOCK REVEALED BY BIOLUMINESCENCE \\ Hiroki R. Ueda. (RIKEN, Center for Developmental Biology (CDB))}

The logic of biological networks such as circadian clocks is difficult to elucidate without (1) comprehensive identification of network structure, (2) prediction and validation based on quantitative measurement and perturbation of network behavior.

First, to identify structure of mammalian clock, we comprehensively determined the transcriptional regulatory circuits composed of 20 transcription factors, and three type of DNA elements including "morning" element (E-box), "day-time" element (D-box) and "night-time" element (RevErbA/ROR binding element, RRE $)^{1,2}$. The following quantitative measurement and static perturbation of clock circuits revealed that E-box/E'-box regulation represents a topological and functional vulnerability in mammalian circadian clocks ${ }^{2,3}$

Second, toward realizing perturbation of mammalian clock, we implemented photo-responsiveness within mammalian cells. We report that the state of clocks can be regulated by light pulses. We reveal that a critical light pulse drives cellular clocks into a singularity behavior where robust circadian rhythmicity can be abolished after a certain stimulus. Theoretical analysis and single-cell-level observation predicts consistently and proves directly that desynchronization of individual cellular clocks underlies this singularity behavior ${ }^{4}$

\section{Reference}

1. Ueda, H.R. et al, Nature 418, 534-5392002

2. Ueda, H.R. et al, Nat. Genet 37, 187-192 2005

3. Sato T K, et al, Nat Genet 38:312-9 2006

4. Ukai H, et al, Nat Cell Biol 9:1327-34 2007

\section{S3-7 多色多様な生物発光の応用と今後の展開}

\section{POTENTIAL OF ADVANCED BIOLUMINESCENCE SYSTEM IN LIFE} SCIENCE TECHNOLOGY

Yoshihiro Ohmiya (Hokkaido University, Graduate School of Medicine)

In the post genome era, molecular imaging based on luciferase technology is an essential approach to understanding the physiological system of the whole animal. We have been creating new luciferase technologies based on the novel bioluminescence system to solve the secret of the life science. For example, using beetle luciferases that emit various colours with a luciferin, we developed a revolutionary tricolour reporter in vitro assay system in which three gene expressions is monitored simultaneously using green-, orange- and red-emitting beetle luciferases. This system could be utilized for detailed analysis in the new fields of transcriptome and promoterome, as well as in pharmacology or toxicology for the screening of new drugs or the detection of harmful chemicals. We also have cloned a secreted-type luciferase (CLuc) from the marine ostracod Cypridina noctiluca. This high activity of Cluc is expected to be beneficial to the high-sensitivity and high-resolution monitoring of gene expression in living cells. The secreted ostracod luciferase presents a significant advantage as a non-destructible bioluminescent reporter. Addition, we developed a simple yet efficient method for the synthesis of (S)-ostracod luciferin. Furthermore, we created the novel CLuc bioluminescence which emit light from ultraviolet to near infrared using (S)-ostracod luciferin analogues or BRET system. The colour difference in the ostracod bioluminescence system is expected to increase the potential for new applications.

\section{S4-1 水中におけるATPの加水分解エネルギ一とは何か?}

What makes ATP hydrolysis energetically favorable in aqueous phase? Scope and implication

Takao Kodama (Dept Bioscience \& Bioionformatics, Faculty of Computer Sci \& Systems Engineering, Kyushu Institute of Technology)

A number of theories have been proposed to explain a favorable Gibbs energy change $\left(\Delta_{\text {hyd }} G^{\circ}<0\right)$ for hydrolysis of ATP into ADP and inorganic phosphate (Pi). Although none has yet been through rigorous verifications, one originally proposed by George et al. (BBA 223:1 '70) is most reasonable but least popular in textbooks. It says that the very difference in the hydration energy between reactants $\left(\mathrm{ATP}+\mathrm{H}_{2} \mathrm{O}\right)$ and products $(\mathrm{ADP}+\mathrm{Pi})$ would principally contribute to $\Delta_{\text {hyd }} G^{\circ}$, hence categorically distinct from others that either ignore or at most regard water as a continuous dielectric for calculation. Moreover, the theory won't require any ad hoc assumption to account for a marked variation of $\Delta_{\text {hyd }} G^{\circ}$ as a function of $\mathrm{pH}$ with which reactants and products undergo successive matching ionizations. For myosin ATP hydrolysis cycle, we know $\Delta G, \Delta H$ and $\Delta S$ values for (1) ATP-binding, (2) ATP-hydrolysis, (3) Pi-release and (4) ADP-release steps (Physiol Rev 65:467 '85). These observed values are all admittedly energetic trade-offs of many different sources, but the dehydration of ATP seriously matters to step 1 and the hydration of $\mathrm{Pi}$ and ADP to steps 3 and 4, respectively. More importantly, $\Delta G_{1}+\Delta G_{4}$ almost equals $\Delta_{\text {hyd }} G^{\circ}$, which does not seem fortuitous. Thus, if we are to envisage the physical meaning of $\Delta_{\text {hyd }} G^{\circ}$ for myosin as a chemo-mechanical energy converting protein, we must rise to the challenge of solution chemistry to refine the theory, more specifically to estimate $\Delta G$ values (preferably $\Delta H$ or $\Delta S$ values as well) for the hydration of ATP, ADP and Pi.

\section{S4-2 1 分子計測から観た ATP 加水分解反応}

How can a single motor-protein molecule sense and utilize the energy of ATP hydrolysis for mechanical work?

Hiroto Tanaka. (PRESTO, JST)

Single molecule measurements (SMMs) have been applied to myosin (molecular motor) to measure its sliding movement along an actin filament. Thus, position of myosin can be determined with $\mathrm{nm}$ and msec accuracy. It is shown that during single ATP hydrolysis cycle, myosins II and V repeat several cycles of attaching to and detaching from an actin filament to generate sliding motion, suggesting that myosins utilize the ATP energy through a multi-step conversion process which cannot be explained by conventional "lever-arm model". The key intermediate is the one with bound hydrolysis products (ADP+Pi), which is kinetically very stable when no interaction occurs with actin and probably the most dehydrated state in myosin ATP hydrolysis cycle (Biophys J 72: 18, '97). It is of critical importance to energetically correlate these characteristics with the multi-step conversion of the ATP energy. Toward this end, we must evaluate both energy input and output at single molecule level (SML). The SMM techniques can quantitatively estimate the output as the mechanical energy. For the input however, there is no method available to do so. We must even define the counterpart at SML for the free energy of ATP hydrolysis in solution. Cooperation between experimental and theoretical approaches is essential to tackle these fundamental problems for understanding of the mechanism of chemo-mechanical energy conversion in bio-molecules, which hopefully provides us with many ideas and clues to construct novel flexible bio-mimetic systems. 